\title{
LA PARTICIPACIÓN DEL ESTADO EN LA PLUSVALÍA COMO UNA DEUDA CIUDADANA
}

\author{
THE PARTICIPATION OF THE STATE \\ IN THE CAPITAL GAIN AS A CITIZEN'S DEBT
}

\author{
VANESSA GARZÓN ZABALA* \\ Recibido: 20 de mayo de 2019 - Aceptado: 15 de junio de 2019 \\ Publicado: 30 de julio de 2019 \\ DOI: $10.24142 /$ raju.v14n28a10
}

\section{Resumen}

La participación del Estado en la plusvalía del suelo derivada de la acción urbanística es un mecanismo constitucionalmente legítimo en la recaudación de ingresos del patrimonio público, para promover el desarrollo urbanístico de los territorios. Por tanto, la línea argumentativa parte de justificar que la captación de los dineros provenientes de este instrumento es un asunto de equidad ciudadana, apoyándose en el principio de la función social en la propiedad y el enriquecimiento sin causa de particulares propietarios y poseedores. Posteriormente, se hace una breve contextualización de la recuperación de plusvalías a nivel internacional, para exponer dos casos exitosos en Brasil y Uru-

* Miembro de la Rama Judicial de Colombia, Especialista en Derecho Público de la Universidad EAFIT, Medellín; Especialista en Derecho Urbanístico de la Universidad de Antioquia, Medellín; Abogada de la Universidad Autónoma Latinoamericana UNAULA, Medellín. Correo electrónico: vanessagaza@hotmail.com 
guay. Y finalmente, se determina la viabilidad de promover acciones judiciales efectivas para el cobro de la participación de la plusvalía.

Palabras clave: plusvalía, función social de la propiedad, enriquecimiento sin causa, acción urbanística, interés general y acción de cumplimiento.

\section{Abstract}

The participation of the State in the capital gain of the land derived from the urban development action is a constitutionally legitimate mechanism in the collection of income from the public patrimony, to promote the urban development of the territories. Therefore, the argumentative line starts from justifying that the collection of money from this instrument is a matter of citizen equity, based on the principle of social function in property and the enrichment without cause of private owners and holders. Subsequently, a brief contextualization of the recovery of capital gains at an international level is made, to present two successful cases in Brazil and Uruguay. And finally, the viability of promoting effective judicial actions to collect the capital gain is determined.

Keywords: goodwill, social function of property, enrichment without cause, urban action, general interest, compliance action. 


\section{INTRODUCCIÓN}

Este artículo presenta los fundamentos constitucionales y legales vigentes en nuestro ordenamiento jurídico, que dan cimiento a la participación de las administraciones municipales en la plusvalía que generen las acciones urbanísticas, así como la justificación para su recuperación, el contexto internacional y las medidas judiciales efectivas para obligar a su recaudación.

Tradicionalmente se ha considerado que el desarrollo de las ciudades es responsabilidad del Estado, representado por las administraciones y concejos municipales de cada urbe. En efecto, a la luz de lo establecido en la Constitución Política, le compete a los consejos municipales reglamentar los usos del suelo, y a las administraciones municipales y distritales les corresponde formular el respectivo Plan de Ordenamiento Territorial (POT), el cual deberá ser aprobado por el Consejo municipal. Adicionalmente, las alcaldías deben contar con un Plan de Gobierno en el cual basarán su gestión y donde se planificarán los objetivos de su periodo.

Sin embargo, el planteamiento del desarrollo urbano como responsabilidad del Estado no es absoluto. Desde la expedición de la actual Constitución Política de 1991, inspirada en principios como la prevalencia del interés general, la propiedad privada dejó de ser un derecho fundamental y pasó a ser una función social que implica obligaciones en beneficio de la sociedad (República de Colombia, 1995). Es decir, la propiedad es un derecho restringible, en favor del interés general y limita las facultades del propietario. En ese sentido, cuando se habla de desarrollo urbano — en beneficio del interés general - también debe hablarse de la corresponsabilidad entre el Estado y los propietarios.

Valga anotar que, si en desarrollo de una obra pública se presenta una afectación a un predio privado, el Estado debe indemnizar al particular, toda vez que la función social de la propiedad contenida en la Constitución no implica per se el desconocimiento de los derechos de los propietarios, ni la exoneración del Estado de indemnizar en favor de quien resulte lesionado. Ahora, piénsese en la situación contraria; ¿qué pasa cuando la acción urbanística estatal beneficia al predio particular? ¿El Estado también le puede solicitar al particular una indemnización por ese beneficio que obtuvo sin ningún esfuerzo suyo? y si es viable el reclamo, ¿cuál será el instrumento más efectivo para su captación y a qué destinar estos recursos? ¿Se pueden reclamar por medio de una acción legal? 
La respuesta a estos interrogantes constituyen el propósito principal de este artículo. Efectivamente, es por medio de la participación del Estado en la plusvalía del suelo, consagrada en el artículo 82 de la Constitución Política, que las administraciones municipales pueden participar del mayor valor que se genere con las acciones urbanísticas, tales como: clasificación del suelo, cambio de uso, mejor aprovechamiento en índice de ocupación o de densidad, o la construcción de una obra pública.

No obstante lo anterior, si bien existen los fundamentos constitucionales y legales para la recuperación de las plusvalías en nuestro territorio, no es común que las administraciones municipales utilicen este instrumento para recuperar el beneficio económico logrado con la acción del Estado, recursos que podrían ser utilizados en el desarrollo de infraestructura y equipamientos de carácter colectivo requeridos por la ciudad.

De hecho, el artículo 85 de la ley 388 de 1997 se encarga de limitar la destinación del producto de la participación en la plusvalía a favor de los municipios para la compra de predios para vivienda de interés social, al mejoramiento de la infraestructura vial, a la ejecución de proyectos de recreación comunitaria, parques y zonas verdes, al pago de indemnizaciones por adquisición de inmuebles para programas de renovación urbana y para el fomento y mantenimiento de su patrimonio cultural.

El hecho de no recuperar el beneficio económico que puede generar la participación en plusvalía a favor del Estado, genera un desbalance en la economía municipal, pues la inversión realizada debería retornar propiciamente al patrimonio público, sobre todo cuando existen normas que habilitan su recaudación, y no ser entregada de manera injusta a manos de los particulares propietarios y poseedores.

En razón a lo planteado, el presente artículo tiene como intención determinar cuáles son las medidas más efectivas para hacer que las autoridades municipales hagan uso de la prerrogativa contenida en el artículo 82 de la Constitución Política, a favor del desarrollo urbano y el interés general.

Para lograr el propósito planteado en este artículo, se presentarán cuatro subtemas. El primero expondrá cronológicamente las normas que habilitan la captación de la plusvalía del suelo; el segundo explicará la justificación de la participación de la plusvalía como deuda social; el tercero se centrará en el análisis de casos a nivel internacional y el cuarto establecerá los mecanismos legales efectivos para obligar a las administraciones municipales la participación en plusvalía del suelo. 


\section{NORMAS QUE HABILITAN LA CAPTACIÓN DE LA PARTICIPACIÓN DE PLUSVALÍ́A DEL SUELO EN COLOMBIA}

En la Reforma Constitucional de 1936, la propiedad privada no se entendió como una función social, sin embargo, sí se reconoció que este derecho debía consultar los intereses sociales para efectos de recibir la protección constitucional que el Estado le garantiza, así:

Cuando de la aplicación de una ley expedida por motivos de utilidad pública, resultaren en conflicto los derechos de particulares con la necesidad reconocida por la misma ley; el interés privado deberá ceder al interés público. Pero las expropiaciones que sea preciso hacer requieren plena indemnización (República de Colombia, 1936, art. 33).

Significa entonces que, desde 1936 se avaló la postura que ante un conflicto entre el interés particular y el interés general debe ceder el primero con plena indemnización.

Ahora bien, durante los años 1970 y 1989 se intentó la aprobación en el Congreso de la República de distintos proyectos de ley de reforma urbana, los cuales no fueron aprobados por una férrea oposición de los sectores conservadores, respaldados por potentes intereses privados incluyendo a la industria de la construcción y promotores inmobiliarios (Pinilla, 2003).

Sin embargo, fue tal la insistencia y necesidad de una reforma urbana, que el 11 de enero de 1989 se promulgó la ley $9,{ }^{1}$ cuyo artículo 106 denominaba la participación en plusvalía como una "contribución de Desarrollo Municipal" obligatoria para los municipios con más de 100.000 habitantes, y optativa para los Consejos Municipales en aquellas zonas con menos habitantes. Esta contribución de orden nacional, pero cedida en favor de los municipios, estaría a cargo de los propietarios o poseedores de aquellos predios o inmuebles urbanos o suburbanos, cuyo terreno adquiera una plusvalía como consecuencia del esfuerzo social o del Estado. Para efectos de la liquidación el artículo 109 indicaba:

1 "Por la cual se dictan normas sobre planes de desarrollo municipal, compraventa y expropiación de bienes y se dictan otras disposiciones". Conocida como la Ley de Reforma Urbana (República de Colombia, 1989). 
Artículo 109.- Derogado Artículo 138 Ley 388 de 1997 decía así: para liquidar la Contribución de Desarrollo Municipal, el mayor valor real del terreno se establecerá por la diferencia entre un avalúo final y otro inicial. Como deducción se le aplicará una proporción del avalúo inicial igual a aquella en que se haya incrementado el índice nacional promedio de los precios al consumidor, ocurrido durante el periodo comprendido entre los dos avalúos.

Cuando exista la capacidad técnica podrá encomendarse la estimación de la plusvalía de que trata el presente artículo al Instituto Geográfico Agustín Codazzi y a las oficinas de Catastro de Bogotá, Cali, Medellín y Antioquia. Estas determinarán el mayor valor por metro cuadrado de terreno producido por los hechos generadores de plusvalía. Al hacerlo, tendrán en cuenta los costos históricos de la tierra y las condiciones generales de mercado. Este valor se ajustará anualmente según los índices de precios y las condiciones del mercado inmobiliario para las zonas valorizadas.

El mayor valor liquidado se dividirá por tres (3) y la tercera parte resultante será el monto de la contribución. Para establecer la suma por cobrar, del monto se descontarán los pagos efectuados durante el periodo comprendido entre la ocurrencia del hecho generador y el momento de la captación del beneficio, por concepto del impuesto predial y sus sobretasas, de la contribución ordinaria de valorización y del impuesto de estratificación socioeconómica.

Parágrafo $1^{\circ}$.- Como avalúo inicial se tendrá el que figure para los terrenos en el avalúo catastral vigente en el momento de producirse el hecho valorizador. Sin embargo, el propietario o poseedor podrá solicitar, dentro de los noventa días siguientes, la actualización del avalúo catastral. Como avalúo final se tendrá el administrativo especial que practique el Instituto Geográfico Agustín Codazzi o la autoridad catastral, respecto a los mismos terrenos, en la fecha de la captación del beneficio.

Parágrafo $2^{\circ}$.- En la actualización del avalúo inicial que figure en el catastro, la entidad competente no tendrá en cuenta el efecto de mayor valor producido por el hecho generador de la plusvalía.

Parágrafo $3^{\circ}$.- La liquidación podrá ser impugnada por el contribuyente o por el personero, en los mismos términos y procedimientos establecidos por el artículo 9 de la Ley 14 de 1983.

Sin embargo, no existe registro del cobro de esta contribución especial en nuestra ciudad. 
Casi dos años después, fue promulgada nuestra actual Constitución Política de 1991 en la cual se indica que Colombia es un Estado Social de Derecho, y en razón a esto, se profirieron una serie de reconocimientos sociales. También se aclaró el panorama en punto a la consolidación del derecho urbanístico en el país, toda vez las normas de desarrollo territorial ya tendrían soporte constitucional, por ejemplo, una serie de artículos se encargaron de definir las competencias en materia de desarrollo territorial.

Ahora, respecto el tema relacionado con este trabajo, el artículo 58 ubicado en el segundo capítulo "De los derechos sociales, económicos y culturales", reconoció el derecho a la propiedad y también estableció sus límites, así:

Se garantizan la propiedad privada y los demás derechos adquiridos con arreglo a las leyes civiles, los cuales no pueden ser desconocidos ni vulnerados por leyes posteriores. Cuando de la aplicación de una ley expedida por motivos de utilidad pública o interés social, resultare en conflicto los derechos de los particulares con la necesidad por ella reconocida, el interés privado deberá ceder al interés público o social.

La propiedad es una función social que implica obligaciones. Como tal, le es inherente una función ecológica.

El Estado protegerá y promoverá las formas asociativas y solidarias de propiedad.

Por motivos de utilidad pública o interés social definidos por el legislador, podrá haber expropiación mediante sentencia judicial e indemnización previa. Este se fijará consultando los intereses de la comunidad y del afectado. En los casos que determine el legislador, dicha expropiación podrá adelantarse por vía administrativa, sujeta a posterior acción contenciosa-administrativa, incluso respecto del precio.

A su vez, el artículo 82 ibídem reiteró que el interés público prevalece sobre el interés particular y habilitó a las entidades públicas a participar en "la plusvalía que genere su acción urbanística y regularán la utilización del suelo y del espacio aéreo urbano en defensa del interés común".

Ante la necesidad de actualizar nuestras bases normativas a la luz de la nueva Constitución Política, se expidieron diferentes leyes que pusieran en marcha los derechos reconocidos en la Carta Magna, entre estas, la ley 388 de $1997^{2}$ o Ley de Ordenamiento Territorial. Esta ley modificó y derogó

2 Por la cual se modifica la ley 9 de 1989 y la ley 2 de 1991, y se dictan otras disposiciones. 
algunos de los temas que traía la ley 9 de 1989, y además estableció una serie de instrumentos de gestión urbana (instrumentos de planeamiento, actuación, financiación y control) para el desarrollo de las ciudades.

En efecto, esta ley dispuso que los municipios, distritos y las áreas metropolitanas que por efectos de la regulación de las diferentes actuaciones urbanísticas deben realizar acciones urbanísticas que generen mayor valor para los inmuebles, quedarían autorizados a establecer la participación en plusvalía (artículo 36). Así, en el capítulo IX se regula el tema de la participación en plusvalía en lo que tiene que ver con hechos generadores, efecto plusvalía, liquidación, exigibilidad y cobro, formas de pago y destinación de recursos.

El artículo 74 señaló que los hechos generadores de la participación en plusvalía serían las decisiones administrativas tomadas en el respectivo Plan de Ordenamiento, o en los instrumentos que lo desarrollen, y que autoricen a: destinar el inmueble a un uso más rentable, o bien incrementar el aprovechamiento del suelo permitiendo una mayor área edificada. Y el artículo 87 agregó que habría participación en plusvalía por ejecución de obras públicas previstas en el РОт, en los planes parciales o en los instrumentos que los desarrollen, y no se haya utilizado para su financiación la contribución de valorización.

Los artículos 75 a 77 establecieron el procedimiento para el cálculo del efecto plusvalía por la incorporación del suelo rural al de expansión urbana, o de la clasificación de parte del suelo rural como suburbano, el cambio de uso y el mayor aprovechamiento del suelo. El efecto plusvalía se determinará por metro cuadrado para cada una de las zonas o subzonas geoeconómicas homogéneas objeto de la participación, y la liquidación de su monto se realizará dentro de los cuarenta y cinco (45) días siguientes. A partir de esta fecha, la administración municipal contará con un plazo de treinta (30) días hábiles para expedir el acto administrativo que determina su monto, contra el cual solo puede interponerse el recurso de reposición. Este acto administrativo deberá ser notificado de manera personal a los propietarios o poseedores, o subsidiariamente, complementado con tres (3) avisos publicados en ediciones dominicales de periódicos de amplia circulación en el municipio o distrito, así como a través de edicto fijado en la sede de la alcaldía correspondiente.

La exigibilidad de la participación en plusvalía será en el momento que el propietario o poseedor del inmueble, respecto del cual se haya declarado un efecto de plusvalía, solicite una licencia de urbanización o construcción, efectúe el cambio de uso del inmueble o realice cualquier acto que implique transferencia del dominio sobre el inmueble (artículo 83). 
Valga mencionar que las disposiciones de participación en plusvalía contenidas en la ley 388 de 1997 fueron reglamentadas por el decreto 1599 de 1998 derogado por el artículo 7 del decreto 1788 de 2004.

Ahora bien, teniendo en cuenta que en cabeza de los municipios y distritos estaba la obligación de reglamentar el tema de la participación en plusvalía, en la ciudad de Medellín se definieron los lineamientos y las competencias para regular la operatividad del cálculo y liquidación de la participación del efecto plusvalía, a través del decreto 752 del 25 de abril de 2013. En esta norma se destaca, por ejemplo, que la asignación de competencias se radicó en cabeza de sus dependencias para regular la operatividad del cálculo y liquidación de la participación del efecto plusvalía, así:

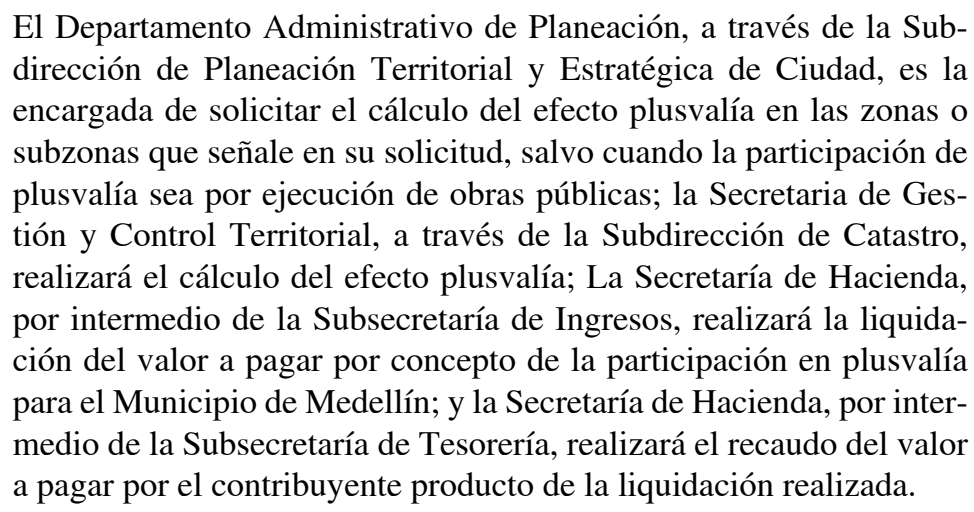

Cuando se trate de la ejecución de obras públicas, la solicitud del cálculo del efecto plusvalía se podrá solicitar a la Subdirección de Catastro Dependencias, a la Secretaría de Infraestructura Física del Municipio de Medellín, o en quien el alcalde de la ciudad delegue su ejecución.

Como novedad, y pese a que el parágrafo 4 del artículo 83 de la ley 388 de 1997 le otorga la facultad a los municipios de "exonerar del cobro de la participación en plusvalía a los inmuebles destinados a vivienda de interés social”, el decreto municipal de Medellín va más allá. En efecto, el artículo 16 , parágrafo 5 del decreto municipal, indica que no habrá lugar a la exigibilidad y cobro de la participación en plusvalía para los casos donde los modos de adquirir el dominio sean la sucesión por causa de muerte o la prescripción adquisitiva de dominio. Tampoco cuando se lleve a cabo la liquidación de la sociedad conyugal o la liquidación de la sociedad patrimonial entre compañeros permanentes, o la liquidación de la sociedad comercial o civil o 
ante cesión obligatoria anticipada a favor del Municipio de Medellín u otra entidad pública.

Adicionalmente, el artículo 20 del decreto aludido habilita al Alcalde de Medellín para que, a través del Departamento Administrativo de Planeación, si decide no aplicar la participación en el efecto plusvalía a una zona o subzona debidamente determinada, motive debidamente, en un acto administrativo y por medio de la Subsecretaría de Tesorería, a través de resolución, a ordenar la devolución de lo hasta ese momento recaudado.

Ahora bien, tal como lo indica la ley 388 de 1997 son los concejos municipales y distritales quienes establecen, mediante acuerdos de carácter general, las normas para la aplicación de la participación en la plusvalía en sus respectivos territorios. Por esto, en el POT vigente para la ciudad de Medellín - acuerdo 48 de 2014—, se estableció en cuanto a la plusvalía lo siguiente:

El artículo 523 determinó que el porcentaje de participación en las plusvalías será el $30 \%$ del incremento del valor del suelo causado por los hechos generadores. Por su parte, el artículo 524 determinó que el municipio de Medellín participará en la plusvalía generada en aquellos lotes que cambiaron el uso social obligado, para permitir un aprovechamiento mayor del suelo; mediante la cesión en sitio de una porción de suelo equivalente al pago del efecto plusvalía más las obligaciones urbanísticas propias del tratamiento urbanístico en una proporción no menor del 50\% del área bruta del lote, con el fin de constituir parques públicos.

Describió que los lotes son:

Tabla 9.1 Lotes que participarán en plusvalía por cambio de uso

\begin{tabular}{|l|l|}
\hline \multicolumn{1}{|c|}{ Predio } & \multicolumn{1}{c|}{ Cambio de uso del suelo } \\
\hline Cuarta Brigada & $\begin{array}{l}\text { Sobre la calle 50 (Colombia), corredor de alta intensidad y } \\
\text { el resto del predio baja mixtura }\end{array}$ \\
\hline $\begin{array}{l}\text { Escuela de Carabine- } \\
\text { ros Carlos Holguín }\end{array}$ & $\begin{array}{l}\text { Alta mixtura - áreas de actividad económica en transfor- } \\
\text { mación }\end{array}$ \\
\hline Colegio Palermo & Alta mixtura - centralidad con predominancia económica \\
\hline Lote Emaús & Media mixtura \\
\hline Ciudad Don Bosco & Baja mixtura \\
\hline
\end{tabular}

Fuente: elaboración propia. 


\section{JUSTIFICACIÓN DE LA PARTICIPACIÓN DE LA PLUSVALÍA COMO DEUDA SOCIAL}

Tal como quedó plasmado en líneas precedentes, en nuestro país se encuentran vigentes las normas constitucionales y legales que habilitan a las administraciones municipales a participar en la plusvalía que genera el suelo de los propietarios y poseedores de un predio, como consecuencia de una actuación de una entidad pública en materia de uso del suelo u obra pública, y que representa un mayor valor de sus propiedades, rendimientos o utilidades.

Dichas normas buscan que los beneficios obtenidos por la acción urbanística del Estado no se queden solo en las arcas de unos particulares, sino que de los mismos participe en forma equilibrada la ciudadanía en general a través del Estado, de manera que los ingresos logrados con la participación en la plusvalía se puedan destinar a la protección del interés común, al espacio público y, en general, al mejoramiento urbano del municipio o distrito. En otras palabras, con la normativa que habilita la participación del Estado en la plusvalía, se busca lograr un reparto equitativo de cargas y beneficios, que en nuestra ciudad se encuentran tan desigualmente distribuidos.

En un Estado Social de Derecho como el nuestro, en donde la propiedad es una función social que implica obligaciones, no puede aceptarse que los incrementos en los precios de los terrenos de propiedad privada constituyan una transferencia gratuita de la sociedad a unos agentes particulares —no población vulnerable—, sin que exista ninguna una contraprestación. Entonces, para evitar que esto suceda se ha previsto la participación del Estado en la plusvalía, para que la sociedad recupere al menos una parte de estos aumentos de valor del suelo; en el caso de Medellín será el 30\% del incremento del valor del suelo causado por los hechos generadores, y el 70\% restante quedará en manos de los particulares propietarios o poseedores.

En este punto, vale la pena preguntarse ¿si la participación del Estado en la plusvalía en un porcentaje de $30 \%$ corresponde a los valores sociales y de equidad que pretendió el constituyente y el legislador con la norma? Frente a este interrogante pueden existir opiniones contrarias; por un lado, quienes consideran que el porcentaje debería ser mayor, pues ese incremento en el precio del suelo se obtuvo con total inacción de los particulares y solo con el esfuerzo estatal, y por el otro, quienes lo consideren como un abuso y una intervención del Estado en la propiedad privada. Sin embargo, 
en armonía con lo planteado en la justificación de la captación de la plusvalía, debe decirse que el reconocimiento de la participación del Estado, así sea solamente en un $30 \%$ del incremento de valor del suelo, es al menos un logro para la sociedad.

La captación de los dineros provenientes de este instrumento son entonces un asunto de equidad ciudadana, o mejor, un instrumento que busca la reducción de la desigualdad social en las ciudades y que tiene como objetivo principal alcanzar mayores niveles de bienestar para el conjunto de la población y no solo para unos pocos. En otras palabras, es invertir el esfuerzo estatal en la sociedad de manera equitativa y para la población que más requiere la intervención del Estado.

Recuérdese que la destinación de los dineros provenientes de la participación en plusvalía deja entrever los valores de equidad y solidaridad social que encierran este instrumento. Ciertamente, el artículo 85 de la ley 388 de 1997 autoriza que sea para: compra de predios o inmuebles para desarrollar planes o proyectos de vivienda de interés social; construcción o mejoramiento de infraestructuras viales, de servicios públicos domiciliarios, áreas de recreación y equipamientos sociales para la adecuación de asentamientos urbanos en condiciones de desarrollo incompleto o inadecuado; ejecución de proyectos y obras de recreación, parques y zonas verdes y expansión y recuperación de los centros y equipamientos que conforman la red del espacio público urbano; financiamiento de infraestructura vial y de sistemas de transporte masivo de interés general; actuaciones urbanísticas en macroproyectos, programas de renovación urbana u otros proyectos que se desarrollen a través de unidades de actuación urbanística; pago de precio o indemnizaciones por acciones de adquisición voluntaria o expropiación de inmuebles, para programas de renovación urbana; fomento de la creación cultural y mantenimiento del patrimonio cultural del municipio o distrito, especialmente en las zonas de la ciudades declaradas como de desarrollo incompleto o inadecuado.

Para ejemplificar cómo la participación del Estado en la plusvalía puede contribuir con la equidad ciudadana, se pone el caso de la ejecución de un proyecto de parques con zonas verdes - la recuperación del espacio público-, en el cual la ciudadanía en igualdad de condiciones tendrá un lugar de encuentro en el que pueden confluir los diferentes sectores de la población, logrando de esta manera el reconocimiento y la aceptación del otro a partir de sus diferencias. Para lograr una equidad ciudadana es preciso fortalecer lo público, y evitar que un sector se autoexcluya de la vida ciudadana encerrándose en espacios netamente privados. 
Entonces, si la participación en la plusvalía puede contribuir a la equidad ciudadana, en el lado inverso, el no realizar su captación genera un "enriquecimiento sin justa causa" para los propietarios y poseedores de los inmuebles, y un eventual "detrimento patrimonial" para el Estado.

La teoría del enriquecimiento sin causa consiste básicamente en el enriquecimiento de un patrimonio y el correlativo empobrecimiento del otro (República de Colombia, 2009); en este caso, son los particulares quienes se lucran al incrementarse el valor del suelo, sin haber ejecutado algún esfuerzo para esto. Por su parte, el detrimento patrimonial en los términos del artículo 6 de la ley 610 de agosto 15 de 2000, entendiéndolo como la lesión del patrimonio público, representada en el menoscabo, disminución, perjuicio, detrimento, pérdida, uso indebido o deterioro de los bienes o recursos públicos, o a los intereses patrimoniales del Estado, por acción u omisión de los servidores públicos o por la persona natural o jurídica de derecho privado, que en forma dolosa o culposa produzcan directamente o contribuyan al detrimento al patrimonio público.

Hasta este punto, es posible precisar que existen normas y fundamentos sociales que justifican la participación del Estado en la plusvalía que genere la acción urbanística, sin embargo, es por desconocimiento, o voluntad de los alcaldes de turno - por ser un instrumento impopular-, que no ha sido posible que el Estado participe de esos incrementos de valor del suelo en la dimensión que se debería. Se necesita de una sociedad participe en temas de la gestión pública, ya que el incremento del patrimonio público le interesa a todos los ciudadanos. Recordando que "la mejor distribución territorial de servicios y de infraestructura permite corregir la segregación territorial, siendo esta última una de las principales causas de la falta de cohesión social y de la marginalidad en todos sus aspectos" (CEPAL, 2000, p. 309).

\section{ANÁLISIS DE CASOS INTERNACIONALES}

En el contexto internacional suramericano se pueden encontrar referentes legales que habilitan los Estados a capturar la plusvalía del suelo, pero sin mayor éxito, a excepción de Brasil.

En Uruguay, por ejemplo, existe la Ley de Ordenamiento Territorial y Desarrollo Sostenible (ley 18308, 2008), que en su artículo 46 incluye la participación en plusvalía, llamada ahí como "retorno de las valorizaciones" que permite a la Intendencia Municipal a participar en el mayor valor inmobiliario que derive para dichos terrenos las acciones de ordenamiento 
territorial, ejecución y actuación. Esta participación se materializará a través de la cesión de pleno derecho de inmuebles libres de cargas de cualquier tipo a la Intendencia Municipal para su inclusión en la cartera de tierras, sin embargo, quienes manifiesten su interés y compromiso por edificar los inmuebles que deben ser objeto de cesión, de acuerdo con el instrumento, podrán acordar con la Intendencia Municipal la sustitución de dicha cesión por su equivalente en dinero que será destinado a un fondo de gestión territorial, o bien la permuta por otros bienes inmuebles de valor similar.

De acuerdo con Smolka (2013), desde el año 2001, en el municipio de Montevideo se aplicó el "precio de compensación", incluso antes de la Ley Nacional mencionada, estableciendo un cargo del 10\% sobre el valor total de la propiedad. Empero, en aplicación de este instrumento esta ciudad solo recaudó \$3,8 millones de dólares, alrededor de 2,5\% del presupuesto total de inversión. Por el contrario, en la municipalidad de Maldonado (Uruguay) se ha recaudado \$ 4,5 millones de dólares, algo más del $11 \%$ del presupuesto.

En Brasil existen varios principios relevantes a la recuperación de plusvalías establecidos en el artículo 182 de la Constitución de 1988. En este país fueron creados los Certificados de Potencial Adicional de Construcción (CEPACS) en 1995, en la operación urbana de Faria Lima, sin embargo, solo comenzó a funcionar en 2004 con la aprobación de 2001 del Estatuto de Ciudad, donde se incluyó este instrumento para ser utilizado en todo el territorio brasileño (Ramírez, 2013, p. 19). Esta herramienta ha sido considerada como innovadora para la captura de plusvalías.

La emisión de los CEPACs es realizada por el Poder Público Municipal, y le otorgan al portador unos derechos adicionales de construcción, cambio en la clasificación del suelo, o para cambios en las tasas de ocupación. Estos certificados son aplicados en las Operaciones Urbanas (OU) que son una herramienta de colaboración público-privada para el desarrollo urbano, y por esto, la cantidad de los CEPACS no puede sobrepasar el límite establecido en la ley de cada ou (Sandroni, 2012, p. 10).

Estos certificados son obtenidos vía subastas electrónicas en la Bolsa de Valores, y los ingresos obtenidos son aplicados por la administración en el interior del perímetro de una ou, y de esta forma no se requerirá invertir recursos públicos para realizar obras viales o de otra naturaleza.

De acuerdo con el texto de Paulo Sandroni, en Curitiba (Brasil) se han aprobado ou en las cuales se han utilizado CEPACS con relativo éxito. Uno de estos es la Operación Urbana Consorciada Linha Verde, aprobada mediante la ley 13909 del 19 de diciembre de 2011; en esta se pretende financiar la construcción de una avenida equivalente a: 
La emisión de 2.575.000 CEPACS con valor unitario de $\mathrm{R} \$ 200,00$. El ingreso potencial total, si todos los CEPACS son vendidos por el precio inicial, alcanzaría 515 millones de reales (U\$ 260 millones) de reales con los cuales la Alcaldía de Curitiba 28 pretende financiar la conclusión de la obra. Es decir, estas plusvalías originadas en la valorización de los terrenos linderos a la Avenida serán utilizados en la construcción de la propia avenida (Sandroni, 2012, p. 27).

La emisión de CEPACS en la Operación Urbana Línea Verde busca captar recursos para complementar las obras del sistema vial y de transporte, la recualificación urbanística, la oferta de espacio público y la regularización urbanística (art. 3). En junio de 2012 se realizó la primera subasta de CEPACS en Curitiba, ofertándose 300.000 unidades, de las cuales se vendieron $141.588(47 \%)$ para un ingreso total de $\mathrm{R} \$ 28.317 .600,00$ equivalentes a cerca de 14 millones de dólares.

Como se ve, los resultados de las subastas de los CEPACS en Brasil parecen alentadoras y se convierten en una manera innovadora y efectiva de recuperar las plusvalías generadas por la acción urbanística del Estado. Sin embargo, también existen críticos respecto a esta herramienta, quienes entienden los CEPACS como elementos que subordinan la política pública urbana al mercado inmobiliario, transformando el otorgamiento oneroso del derecho de construir en una fuente complementaria de especulación financiera.

Para Paulo Nascimento y Tomás Antonio Moreira (2013), la Operación Urbana Línea Verde "está más próxima a un mecanismo de dinamización del mercado inmobiliario, que propiamente a un instrumento de fortalecimiento de la función social de la ciudad y de la propiedad" (pp. 85-86).

En concordancia con lo anterior, se puede decir que en Brasil se ha logrado una captura eficiente de las plusvalías a través de la venta de derechos adicionales de construcción; sin embargo, su uso debe estar destinado a una gestión urbana más equitativa, toda vez que si los recursos obtenidos deben ser utilizados en las áreas de la operación urbana, en ocasiones dicho beneficio se destina a las zonas de la ciudad con suficiente infraestructura, impulsando la elevación de los precios de la tierra y estimulando las desigualdades sociales y territoriales en las ciudades.

Por demás, se agrega que desde 1934 la "contribución por mejoras" fue elevada a rango constitucional. Esta la pueden cobrar las entidades de todos los órdenes y se aplica a los propietarios de inmuebles beneficiados con la construcción de obras públicas en general. 


\section{MECANISMOS LEGALES PARA OBLIGAR A LAS ADMINISTRACIONES MUNICIPALES A LA PARTICIPACIÓN EN PLUSVALÍA DEL SUELO}

La plusvalía urbana, como fuente de financiamiento de infraestructura a través de una gestión adecuada en la que se tengan en cuenta los diferentes actores de la ciudad, puede convertirse en un instrumento que promueva la equidad territorial en la ciudad. Para lograrlo, los habitantes deben tomar conciencia y entender que no se trata solamente de un tema de las administraciones municipales, sino un asunto que nos incumbe a todos.

Debemos lograr una mayor cohesión social frente a los temas urbanos, y ser partícipes de cómo queremos construir y planificar la ciudad en que vivimos. A través de la inversión adecuada de los recursos que genere la participación en plusvalía, se debe buscar una política social que promueva la protección y promoción de las oportunidades y de la calidad de vida de los ciudadanos, de manera que sean partícipes de los beneficios y al mismo tiempo actores del desarrollo.

Para lograr esto, la ciudadanía debe empezar a actuar y no esperar a que el gobernante de turno sea el que tome la decisión (por todos) de capturar la participación en la plusvalía generada de las acciones urbanísticas del Estado que regulan la utilización del suelo y del espacio aéreo urbano incrementando su aprovechamiento. En este sentido, los ciudadanos deberíamos emplear los instrumentos constitucionales y legales para cuidar el patrimonio púbico.

Ahora bien, entendiendo que el actual РОт de Medellín considera que la participación en plusvalía es un deber de la administración y no una mera opción, pues así se deriva del numeral $1^{\circ}$ literal j del artículo 449 del acuerdo 48 de 2014 cuando dice:

La Administración Municipal deberá realizar el cobro de plusvalías aplicando el decreto 752 de 2013 o la norma que la modifique o sustituya, entendiendo como hecho generador las obras públicas que se realicen y que no se financien con aportes de obligaciones urbanísticas o con valorización; igualmente, podrá realizar los estudios para el cobro por el hecho generador de cambio de usos donde hubiera lugar. 
También el artículo 524:

La Administración Municipal participará en la plusvalía generada por este hecho generador, mediante la cesión en sitio de una porción de suelo equivalente al pago del efecto plusvalía más las obligaciones urbanísticas propias del tratamiento urbanístico en una proporción no menor del 50\% del área bruta del lote, con el fin de constituir parques públicos.

En este sentido, puede considerarse que la acción de cumplimiento (artículo 87 C. P.) es mecanismo constitucional válido para reclamar de las autoridades municipales el cumplimiento de un acuerdo del concejo municipal, tal como sería el caso del POT en el cual se dispone la participación en plusvalía. Vale aclarar que para su prosperidad deberán acreditarse los siguientes requisitos: 1) Que el deber jurídico cuya observancia se exige esté consignado en normas con fuerza de ley o en actos administrativos; 2) Que el mandato, la orden, el deber, la obligatoriedad o la imposición esté contemplada en forma precisa, clara y actual; 3) Que la norma esté vigente; 4) Que el deber jurídico esté en cabeza del accionado; 5) Que se acredite que la autoridad o el particular en ejercicio de funciones públicas fue constituido en renuencia frente al cumplimiento de la norma o acto administrativo, cuyo acatamiento pretende la demanda y 6) Que tratándose de actos administrativos no haya otro instrumento judicial para lograr su efectivo cumplimiento (República de Colombia, 2017a).

Además de la anterior acción constitucional, la Acción Popular prevista en el artículo 88 de la Constitución Política también puede ser considerada en este caso. Este mecanismo busca la protección de los derechos e intereses colectivos, relacionados con el patrimonio, el espacio, la seguridad y la salubridad, la moral administrativa, el ambiente, la libre competencia económica y otros de similar naturaleza que se definen en ella. En este mismo sentido, el artículo 4 de la ley 472 de 1998 señaló como derechos colectivos, entre otros, los relacionados con: "La moralidad administrativa" y "la defensa del patrimonio público".

Ahora bien, respecto el tema de la participación en plusvalía, se podría instaurar una acción popular como medida de protección de la moralidad administrativa y la defensa del patrimonio público, evitando que con la acción urbanística del Estado, que regula la utilización del suelo y del espacio aéreo urbano, se beneficien solamente unos particulares poseedores 
y propietarios, sin que la ciudad pueda participar de dichos recursos. Sobre el tema del patrimonio público como un derecho colectivo el Consejo de Estado ha indicado:

La regulación legal de la defensa del patrimonio público tiene una finalidad garantista que asegura la protección normativa de los intereses colectivos, en consecuencia, toda actividad pública está sometida a dicho control y si afecta el patrimonio público u otros derechos colectivos podrá ser objeto de análisis judicial por medio de la acción popular. El derecho a la defensa del patrimonio público busca asegurar no solo la eficiencia y transparencia en el manejo y administración de los recursos públicos, sino también la utilización de los mismos de acuerdo con su objeto y, en especial, con la finalidad social del Estado. En tal virtud, si la administración o el particular que administra recursos públicos los manejó indebidamente, ya sea porque lo hizo en forma negligente o ineficiente, o porque los destinó a gastos diferentes a los expresamente señalados en las normas, afectaron el patrimonio público y, por ende, su protección puede proceder por medio de la acción popular (República de Colombia, 2017b, p. 21).

Y más recientemente, la misma Corporación dijo que el patrimonio público como derecho colectivo tiene una doble finalidad: la primera, relativa a prevenir y combatir su detrimento; y la segunda, para que sus elementos sean eficiente y responsablemente administrados. Entonces, frente al incumplimiento de estas dos finalidades es preciso la exigencia de la efectividad de tal derecho colectivo por parte de cualquier miembro de la colectividad (República de Colombia, 2017b).

Ahora bien, en Bogotá existen referentes judiciales de acciones populares interpuestas por unos ciudadanos ante el Tribunal Administrativo de Cundinamarca, ${ }^{3}$ que buscaban hacer efectivo el cobro de la participación en la plusvalía para que se destinase los recursos recaudados según el artículo 85 de la ley 388 de 1997, a fin de evitar un detrimento patrimonial.

Uno de estos es la acción popular, radicada bajo el número 2004-02536 y que fue interpuesta por el señor Mario Raúl Clavijo Ortiz contra el municipio de Bojacá (Cundinamarca), en donde se dictó sentencia denegatoria de las pretensiones, el 27 de octubre de 2005, bajo la siguiente argumentación:

3 Radicados: 25000231500020040253601 y 25000231500020050117801 
Pues bien, revisados los fundamentos normativos de la Plusvalía es claro que el cobro de esta herramienta financiera debe estar basada en el Plan o Esquema de Ordenamiento Territorial que rija en el municipio, y cuyo propósito es el distribuir y sufragar equitativamente los costos del desarrollo urbano, debiendo para el efecto los propietarios de dichos predios compensar el aumento o elevación del precio de su propiedad por las acciones urbanísticas realizadas por la Administración.

Descendiendo al sub - lite, y de acuerdo con el material probatorio aportado al proceso se concluye que en efecto, el Municipio de Bojacá no ha adoptado el cobro de la Plusvalía de aquellos predios que según su E.O.T., se hubieran beneficiado con acciones urbanísticas aprobadas y desarrolladas por el Municipio, enmarcadas dentro de los hechos generadores de tal participación.

Así mismo, aparece acreditado en el expediente que la Administración Municipal no ha sido ajena a la iniciativa de presentar el proyecto ante el Concejo Municipal a fin de que este apruebe el cobro de la Plusvalía (fls. 53 y s.s.) y pese a que los documentos que así lo acreditan datan del año 2002, era carga probatoria que competía al demandante demostrar que con la no adopción del correspondiente reglamento para este efecto, se está incurriendo en la violación de los derechos colectivos que cita como infringidos, pues era de su resorte y de conformidad con la carga que le impone el artículo 30 de la Ley 472 de 1998, probar que con fundamento en el Esquema de Ordenamiento Territorial adoptado por el Municipio demandado, en Bojacá se consolidaron situaciones generadoras de dicha participación según el artículo 74 de la Ley 388 de 1997, toda vez que el cobro de la plusvalía afecta exclusivamente a las personas que reciben un beneficio económico con ocasión de las actividades urbanísticas que aprueben las entidades públicas, esto es, no se trata de un mandato generalizado para toda la población.

$[\ldots]$

Así las cosas y al no estar demostrado ni aportado al expediente el Esquema de Ordenamiento Territorial del Municipio demandado, que acrediten la incorporación de hechos generadores de Plusvalía a predios de esa Localidad, forzoso es concluir que no puede la Sala ordenar la protección invocada, exigiendo a la Administración para que esta realice dicho cobro y destine los recursos que por dicho concepto se reciban a los fines que prevé el artículo 85 de la Ley 388 de 1997 (cursivas fuera del original) (República de Colombia, 2005, pp. 10-13). 
Como se ve, el Tribunal Administrativo de Cundinamarca consideró que era necesario que el municipio de Bojacá contemplara en su Esquema de Ordenamiento Territorial las situaciones generadoras de la participación en plusvalía, para proceder a cobrarla, y como no fue demostrado procedió a denegar las pretensiones de la demanda. Adicionalmente, en esta misma providencia advirtió que la acción de cumplimiento es la herramienta indicada para solicitar el cumplimiento de una ley y no la acción popular instaurada, en palabras de la Corporación:

No es la acción popular el mecanismo judicial idóneo para solicitar el cumplimiento de la Ley, para ello procedería la acción prevista en el artículo 87 de la Constitución Política, cuyo objeto es el de "hacer efectivo el cumplimiento de una ley o un acto administrativo".

Ahora bien, más recientemente el Consejo de Estado se pronunció en segunda instancia en una acción popular interpuesta por la señora Diana Eugenia Ramírez Cuesta, en contra del Municipio de Tenjo (Cundinamarca), y si bien consideró que no se hubiese incurrido en la vulneración de los derechos colectivos, sí indicó que merecía reproche

el hecho de no haberse producido mucho antes la liquidación, por parte del Alcalde de Tenjo, de la participación en la plusvalía sobre cada uno de los predios en los cuales se configuraron los requisitos para ello, lo cual finalmente se hizo el 7 de febrero de 2007, procediéndose incluso al recaudo de parte de lo liquidado para los años 2007, 2008 y 2009 (República de Colombia, 2010, p. 12).

Por demás, indicó que la mera demora del Consejo Municipal en fijar una tasa de participación en plusvalía, ni la tardanza en liquidarse efectivamente el porcentaje de la participación, configuraban una situación lesiva de los derechos colectivos, sino que el actor popular debía acreditar una situación concreta que lesiva a los derechos colectivos de una comunidad, y no de manera generalizada.

Como se ve, la acción popular, como instrumento legal para reclamar de las autoridades el cobro de la participación en plusvalía, no ha tenido éxito en nuestro país, sin embargo, este precedente no significa que sea un instrumento constitucional inadecuado para reclamar de las autoridades municipales el recaudo de los dineros provenientes del mayor valor del suelo generado por la acción urbanística del Estado. Ciertamente, las sentencias 
referenciadas anteriormente, permiten entrever que con la acción popular se puede pedir judicialmente la protección de los derechos colectivos de moralidad administrativa y defensa del patrimonio público, por el no cobro de la participación en plusvalía, solo que como en todo proceso judicial, es la parte accionante quien tiene la carga de probar la vulneración de dichos derechos.

Respecto al tema de la carga de la prueba en las acciones populares, el Consejo de Estado ha indicado:

La acción popular no está diseñada para acudir a ella ante cualquier violación de la ley, irregularidad o disfunción que se presente ya sea en el ámbito público o privado. Por el contrario, como se indicó al inicio de estas consideraciones, la acción popular tiene un papel preventivo o remedial de protección de derechos e intereses colectivos, cuando quiera que estos se ven amenazados o están siendo vulnerados, pero en uno y otro evento, tanto la amenaza como la vulneración, según el caso, deben ser reales y no hipotéticas, directas, inminentes, concretas y actuales, de manera tal que en realidad se perciba la potencialidad de violación del derecho colectivo o la verificación del mismo, aspectos todos que deben ser debidamente demostrados por el actor popular, quien conforme a lo dispuesto en el artículo $30 \mathrm{de}$ la Ley 472 de 1998, tiene la carga de la prueba (Consejo de Estado, 2005b, p. 29).

Teniendo en cuenta las anteriores consideraciones, sí es posible promover acciones constitucionales dirigidas a exigir, de las autoridades municipales, el cobro de la participación de la plusvalía, esto sí, tomando en cuenta los aprendizajes que han dejado los intentos anteriores.

Por un lado, es preciso la participación y empoderamiento de la ciudadanía, lo cual permita que durante la formulación del respectivo plan de ordenamiento territorial, plan básico de ordenamiento territorial o esquema de ordenamiento territorial, según sea el caso, para que en el acuerdo municipal se pruebe la incorporación de hechos generadores de plusvalía a algunos predios de la ciudad, así como la habilitación para que las autoridades puedan exigir de los propietarios o poseedores beneficiados por el aumento o elevación del precio de su propiedad, el cobro de la participación en plusvalía. Es este momento que resulta viable la acción de cumplimiento, para que cualquier ciudadano pueda solicitar ante un juez el efectivo cumplimiento de la ley 388 de 1997 (o un decreto municipal, en caso de que exis- 
tiese, y que para el caso de Medellín es el decreto 752 del 25 de abril de 2013) y de esta manera, se incorpore en el POT, de forma clara, el hecho generador y la autorización para liquidar y capturar los ingresos provenientes de la participación en plusvalía. De esta forma, se lograría evitar que los beneficios otorgados en los planes de ordenamiento se queden solamente en manos de particulares, como sucedió por ejemplo en Medellín con el Plan Parcial de SIMESA o la obra pública Tranvía de Ayacucho del Metro.

Por otro lado, la viabilidad para promover la acción popular será posible una vez se haya logrado la incorporación específica en el POT de los eventos generadores de plusvalía, sin que las autoridades municipales hayan procedido con el deber legal de realizar la liquidación del efecto plusvalía sobre los predios beneficiados, o el cobro de la misma. Y adicionalmente, de acuerdo con la jurisprudencia, para solicitar la protección de los derechos colectivos de la moralidad administrativa y la defensa del patrimonio público debe probarse la amenaza y vulneración de estos derechos.

Pero, ¿cómo se prueba la vulneración a la moralidad administrativa? Sobre esto ha dicho la jurisprudencia que debe demostrarse que el servidor público o particular que ejerce función pública ha actuado en abierto desconocimiento de parámetros éticos y morales con ánimo subjetivo, torticero y malicioso. Y en lo que tiene que ver con la afectación al patrimonio público, ¿bastará con demostrar que la falta de recaudo de los dineros generados por la acción urbanística del Estado representa una gestión antieconómica, ineficaz e ineficiente, que no se ajuste al cumplimiento de los cometidos y de los fines esenciales del Estado? En todo caso, la valoración probatoria dependerá del juzgador y cada caso debe será analizado de manera particular, y no obstante que se visualiza una dificultad probatoria, esto no significa que sea imposible, más bien debe pensarse en tomarse los temas de ciudad más en serio y hacerse un ejercicio juicioso en el momento de instaurar una acción popular.

Por demás, no sobra recalcar que como acción ciudadana también es posible hacer una denuncia ante la Contraloría, a fin de que se inicie un proceso de responsabilidad fiscal con el que se determine la responsabilidad de los servidores públicos, cuando en el ejercicio de la gestión fiscal, o con ocasión de esta, causen por acción u omisión, y en forma dolosa o culposa, un daño al patrimonio del Estado. 


\section{CASO MEDELLÍN}

Con el fin de conocer cuál era la situación del municipio de Medellín con el tema de la participación en plusvalía, sobre todo por el auge inmobiliario en la ciudad y las obras públicas que se han ejecutado en los últimos años, a través del derecho de petición que consagra el artículo 23 de la Constitución Política de Colombia, se solicitó al municipio (derecho de petición que se anexa al presente artículo) que informara sobre lo siguiente:

1) Si a la fecha el municipio de Medellín ha realizado captación de la participación en plusvalía por las acciones urbanísticas que han generado un mayor valor en los predios de particulares, de conformidad con lo dispuesto por el artículo 82 de la Constitución Política, desarrollado en los artículos 73 y siguientes de la Ley 388 de 1997.

2) Si en razón de las acciones urbanísticas realizadas en la ciudad, la Administración municipal ha ordenado a través de un acto administrativo la realización de un estudio por el efecto plusvalía, en los términos de los artículos 75 a 77 de la Ley 388 .

3) Si se ha dado cumplimiento a lo previsto en el artículo 523 y en el numeral 6 del artículo 446 del Acuerdo 48 de 2014 - POT-y en ese sentido el Municipio ha realizado la captación de plusvalías, el cobro de valorización y otras formas de recuperación de plusvalías, originadas por las decisiones normativas de dicho Plan de Ordenamiento Territorial y las obras públicas que se ejecuten.

4) Si en la obra pública denominada "Parques del Río" se hizo el estudio por el efecto plusvalía, en virtud de lo dispuesto en el numeral 1 del artículo 448 y el numeral 1 literales a, i y j del artículo 449 del Acuerdo 48 de 2014 - POT-.

5) Si en la futura obra pública denominada "Tranvía de la 80 " se realizará un estudio por el efecto plusvalía en virtud de lo establecido en el artículo 523 del Acuerdo 48 de 2014 — POT-.

6) Si el municipio de Medellín ha realizado el cobro de la participación de la plusvalía, por la realización de una obra pública. En caso de ser positiva la respuesta se indique cuáles son los casos y cuál fue el monto de la captación realizada, junto con el valor de la obra pública; en caso de ser negativa su respuesta me informe las 
razones por las cuáles no se han tomado las acciones pertinentes para su cobro, a sabiendas que el artículo 87 habilita a las entidades públicas a particular de su cobro.

7) Si ya se realizó el cálculo del efecto plusvalía sobre los lotes relacionados en el artículos 524 del Acuerdo 48 de 2014 (Cuarta Brigada, Escuela de Carabineros Carlos Holguín, Colegio Palermo, Lote Emaús, Ciudad Don Bosco), toda vez que en virtud del aludido Acuerdo, cambiaron el uso social obligado asignado anteriormente por el Acuerdo 46 de 2006 y el régimen urbanístico, permitiendo un aprovechamiento mayor del suelo.

El derecho de petición presentado fue contestado mediante oficio 201730237153 del 27 de septiembre de 2017, en el cual se indicó que la aplicación de la participación en plusvalía se realizó en el Plan Parcial Colinas del Porvenir, debido a los mayores aprovechamientos dados al presentar la aprobación del mismo y el cambio de norma entre los acuerdos 62 de 1999 y el acuerdo 46 de 2006. Además, puso de presente que en el acuerdo 48 de 2014 se aprobó el cambio de uso, permitiendo que cambiaran el uso social obligado asignado por el anterior POT, en los siguientes predios: Cuarta Brigada, Escuela de Carabineros Carlos Holguín, Colegio Palermo, Lote Emaús y Ciudad Don Bosco, e indicó que la administración municipal participará en la plusvalía generada en estos predios mediante la cesión en sitio de una porción de suelo equivalente al pago del efecto plusvalía más obligaciones urbanísticas propias del tratamiento urbanístico, en una proporción no menor del $50 \%$ del área bruta del lote, con el fin de construir parques públicos. Y agregó que:

Adicionalmente se aprobó el Pago en especie como un instrumento que busca la vinculación de inmuebles privados, localizados en áreas de interés recreativo y paisajístico, al Subsistema de espacio público de esparcimiento y encuentro, en virtud del cual, mediante la formulación del Plan Maestro respectivo propuesto por los propietarios de los predios en tratamiento de Áreas de Preservación de Infraestructura -API-, podrá viabilizar la asignación de un aprovechamiento adicional distinto al uso actual del equipamiento, en una proporción no superior al 30\% del área bruta del inmueble considerado como de especial importancia ambiental y en contraprestación por este aprovechamiento adicional, los propietarios deberán ceder en el mismo 
lote, una parte de suelo equivalente al aprovechamiento propuesto en el Plan Maestro y por el efecto plusvalía resultante del cambio de uso. El efecto plusvalía generado por el cambio de uso del suelo, más las obligaciones urbanísticas generadas por el aprovechamiento adicional propuesto por los propietarios en el Plan Maestro adoptado por el Alcalde, se pagarán en el mismo predio.

Aún está por reglamentar la participación en plusvalía por obra pública, al cual debemos definir una metodología que permita establecer el incremento en el valor del suelo que se genera por obra pública, aislando los efectos del mercado inmobiliario y de obras civiles.

Acorde con lo anterior, también mencionó que la Subsecretaría de Catastro ya realizó el cálculo del efecto plusvalía de los lotes relacionados en el artículo 524 del acuerdo 48 de 2014. Sin embargo, en la respuesta al derecho de petición no se indicó cuál es el acto administrativo por medio del cual se realiza esta liquidación, ni tampoco fueron aportados los resultados de la liquidación.

Por otro lado, y con relación a la obra pública "Parques del Río", informó que la información y metodología para financiarla reposa en la Sociedad Parques del Río, encargada de la ejecución, operación, sostenimiento y administración de este proyecto.

Finalmente, dijo:

Si bien el Plan de Ordenamiento Territorial plantea la necesidad de cumplir con la equidad territorial municipal a través de la configuración de un sistema integrado de reparto equitativo de cargas y beneficios, por medio de las herramientas e instrumentos de financiación reglamentados.

Las acciones encaminadas para tal fin se lograran a través del direccionamiento de los recursos provenientes del instrumento hacia áreas de la ciudad con mayores déficits y conforme con las destinaciones establecidas en la ley 388 de 1997.

Los estudios de aplicación de la plusvalía por obra pública darán como resultado si es viable la utilización del instrumento en todas las obras públicas a desarrollar y que se encuentre en concordancia con el cumplimiento del principio de reparto equitativo de cargas y beneficios. También se contrasta con los instrumentos de financiación del suelo incluidos en el Acuerdo 48 de 2014 con el fin de determinar el 
mecanismo más efectivo para el recaudo de la plusvalía generada en estos territorios producto de la obra pública.

Como se desprende de lo anterior, en el municipio de Medellín se ha proyectado la participación en plusvalía en dos eventos. El primero, a través de la captación en dinero de la plusvalía generada en el Plan Parcial Colinas del Porvenir en el barrio Guayabal, y en el segundo surge con la aprobación del actual POT - acuerdo 48 de 2014-, que plantea el cobro de la participación en plusvalía mediante la cesión en sitio de una porción de suelo, con el fin de construir parques públicos, en los lotes relacionados en el artículo 524, debido al cambio de uso social obligado asignado anteriormente a estos.

Sin embargo, en lo que tiene que ver con la obra pública, esta herramienta nunca ha sido utilizada bajo el argumento que falta por definir una metodología que permita establecer el incremento en el valor del suelo generado por la obra pública, aislando los efectos del mercado inmobiliario y de obras civiles

Ahora bien, luego de realizar una indagación, y teniendo en cuenta que solo existe en la ciudad un ejemplo de recaudo en dinero de participación en plusvalía, se realizará una breve referencia del Plan Parcial Colinas del Porvenir, el cual fue aprobado mediante el decreto municipal 473 de 2015, determinándose en el artículo 61 el cobro de la participación en plusvalía para los predios que conforman este Plan Parcial. En este caso, el hecho generador del instrumento fue el "mayor aprovechamiento producto de la modificación de la norma", así:

Tabla 9.2 Modificación de la norma: mayor aprovechamiento

\begin{tabular}{|c|c|c|c|}
\hline Acuerdo (POT) & Densidad & $\begin{array}{c}\text { Índice de } \\
\text { construcción }\end{array}$ & Índice de ocupación \\
\hline Acuerdo 62 de 1999 & N/A & 1,2 & $40 \%$ \\
\hline Acuerdo 46 de 2006 & 275 & 1,5 & $35 \%$ \\
\hline
\end{tabular}

Fuente: elaboración propia.

Como consecuencia de lo anterior, la Subsecretaría de Catastro, mediante los informes AE-0605/01 del 14 de diciembre de 2015 (radicado 201500637721), AE-003 del 22 de enero de 2016 (radicado 201600026243) y AE-003/01 del 15 de febrero de 2016 (radicado 201600071720) determinó el cálculo del efecto plusvalía generada en el Plan Parcial Colinas del Porvenir; cálculo que resumió de la siguiente manera: 
La participación del Estado en la plusvalía como una deuda ciudadana

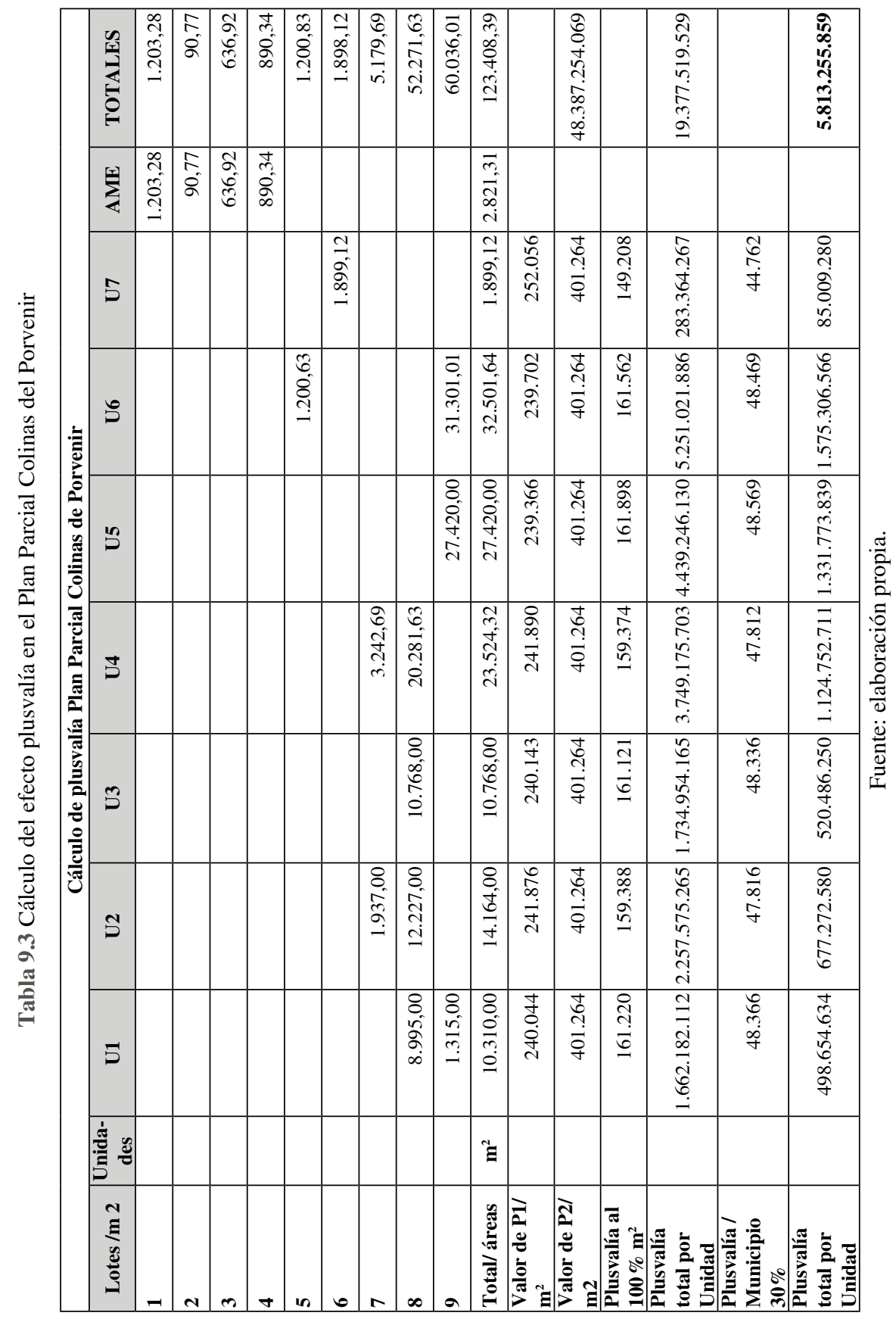


Entonces, de acuerdo con el cálculo realizado por la Subsecretaría de Catastro, el valor de la plusvalía esperada por la ciudad del Plan Parcial Colinas del Porvenir asciende a la suma de \$5.813.255.859.

Como consecuencia de lo anterior, sobre cada inmueble que conforma el plan parcial le correspondía a la Secretaría de Hacienda - Subsecretaría de Ingresos del Municipio de Medellín, realizar la liquidación del efecto plusvalía. En efecto, sobre el inmueble con matricula inmobiliaria 22023, y que hace parte de la Unidad de Actuación 5 del Plan Parcial Colinas del Porvenir, fue expedida la resolución 31913 del 30 de marzo de 2016, por medio de la cual se liquidó la participación en plusvalía del lote aludido en la suma de \$58.192.855, lo cual se detalló de la siguiente manera:

Tabla 9.4 Liquidación del efecto plusvalía del inmueble con matricula inmobiliaria 22023

\begin{tabular}{|l|l|}
\hline Predio & 5 \\
\hline Matricula Inmobiliaria & 22023 \\
\hline Área total $\left(\mathrm{m}^{2}\right)$ & $1.200,63$ \\
\hline Valor P1 (base cálculo plusvalías) / $\mathrm{m}^{2}$ & $\$ 239.702$ \\
\hline Valor P2 (avalúo después de plusvalía) / $\mathrm{m}^{2}$ & $\$ 401.264$ \\
\hline Efecto plusvalía (P2 - P1) / $\mathrm{m}^{2}$ & $\$ 161.562$ \\
\hline Efecto plusvalía total para el predio & $\$ 193.976 .184$ \\
\hline Cobro efecto plusvalía municipio $(30 \%)$ & $\$ 58.192 .855$ \\
\hline
\end{tabular}

Fuente: elaboración propia.

Con base en las sumas presentadas anteriormente, se considera que los valores arrojados por la participación en plusvalía no son para nada insignificantes, y que de no haberse implementado el instrumento en este Plan Parcial todo hubiese quedado en manos de unos particulares. Una gestión seria y juiciosa en su recaudo puede colaborar con el desarrollo de la ciudad.

\section{CONCLUSIONES}

Como resultado del artículo presentado, es posible concluir que en el ordenamiento jurídico colombiano existen los fundamentos legales y constitucionales que habilitan a las autoridades municipales a participar de la plusvalía generada en el suelo, por la acción urbanística del Estado. Estas normas tienen como finalidad un reparto equitativo de cargas y beneficios 
de la planificación urbana de la ciudad, para que los incrementos en el valor del suelo obtenidos no solo beneficien a unos particulares, sino que de estos recursos sea partícipe la ciudadanía en general, destinándose a la protección del interés común, al espacio público y, en general, al mejoramiento urbano de la ciudad.

La participación en la plusvalía urbana como fuente de financiamiento es un instrumento que busca contribuir a lograr la equidad territorial en la ciudad y, por tal razón, se debe lograr una mayor cohesión social frente a los temas urbanos, de manera que la sociedad se empodere y empiece a plantearse la necesidad de utilizar los instrumentos constitucionales y legales pasibles, para exigir de las autoridades municipales la utilización y el recaudo de la participación en la plusvalía, en aras de proteger el patrimonio púbico y evitar un eventual detrimento patrimonial.

No obstante, que este es un instrumento que busca la reducción de la desigualdad social en las ciudades y que tiene como objetivo principal, alcanzar mayores niveles de bienestar para el conjunto de la población, y a pesar de encontrarse reglamentada en Colombia desde hace de veinte años, en la ciudad de Medellín, por ejemplo, solo puede hablarse de su implementación en el Plan Parcial Colinas del Porvenir y en el actual POT -acuerdo 48 de 2014-, con el cambio de uso social obligado asignado anteriormente en algunos lotes de la ciudad.

En este punto es preciso preguntarse, ¿qué pasó con el resto de planes parciales aprobados en la ciudad y que han dado lugar al auge acelerado del desarrollo inmobiliario? ¿Acaso no se presentaron hechos generadores de la participación en plusvalía en el resto de los planes parciales, que implicaran su adopción? Tendría que analizarse cada caso para poder afirmar que fue por falta de voluntad o desconocimiento de las autoridades municipales que se desaprovecharon los incrementos de valor generados con la acción urbanística.

Por otro lado, si bien se ha logrado un avance en el tema, ya que con el acuerdo 48 de 2014 quedó aprobado que el municipio de Medellín participará de la plusvalía generada en los predios que cambiaron de uso, permitiendo que cambiaran el uso social obligado asignado por el anterior POT mediante la cesión en sitio de una porción de suelo equivalente al pago del efecto plusvalía, más obligaciones urbanísticas propias del tratamiento urbanístico en una proporción no menor del 50\% del área bruta del lote, con el fin de construir parques públicos. Conviene recordar a los doctrinantes Paulo Nascimento y Tomás Antonio Moreira (2013), cuando en una crítica a 
los CEPACs en Brasil indicaron que "está más próxima a un mecanismo de dinamización del mercado inmobiliario, que propiamente a un instrumento de fortalecimiento de la función social de la ciudad y de la propiedad" (p. 86).

Lo anterior porque los lotes relacionados en el artículo 524 del acuerdo 48 de 2014, que son los generadores de la participación en plusvalía mediante la cesión en sitio de una porción de suelo, son zonas de la ciudad con buena infraestructura y que no requieren con urgencia la intervención urbanística, situación que lleva a elevar aún más los precios de la tierra. Más aun, cuando se decide no privilegiar las zonas de la ciudad con mayores déficits, se está contribuyendo indirectamente a la consolidación de la desigualdad social y territorial en la ciudad — segregación socioeconómica一, contrariando la finalidad de la participación en plusvalía que es el reparto equitativo de cargas y beneficios para alcanzar un mayor nivel de bienestar para el conjunto de la población, permitiendo que todos los ciudadanos sean partícipes de los beneficios y actores del desarrollo de ciudad.

Si bien no deja de ser preocupante lo expuesto en el planteamiento anterior, esto no significa que se deba menospreciar el intento del municipio de Medellín por recuperar la plusvalía generada, mediante la cesión de porciones de suelo que serán utilizadas para la creación de parques públicos. Recuérdese que el espacio público es por excelencia el lugar para la construcción ciudadana, donde confluyen los acuerdos y desacuerdo ciudadanos, donde todos nos encontramos en un plano de igualdad de condiciones, generando equidad territorial. Los espacios públicos son una oportunidad para reconstruirnos como sociedad.

Corolario a lo anterior, se encuentra que la ciudad de Medellín ha dejado muchas deudas ciudadanas y sociales en torno al retorno de la participación en la plusvalía generada por la acción urbanística del Estado; deuda que ha contribuido a la desigualdad territorial de la ciudad. Sin embargo, hay un panorama esperanzador que promete recuperar algunos de esos incrementos en el valor del suelo, en favor de la ciudad, convirtiéndolos en espacios públicos. Aunque la gran deuda que sigue pendiente es la aplicación de la participación de la plusvalía por obra pública, ¿cuánto tiempo debe la ciudadanía esperar a que se reglamente y defina una metodología para su liquidación? 


\section{REFERENCIAS}

CEPAL (2000). Equidad, desarrollo y ciudadanía. Recuperado de https://repositorio.cepal.org/bitstream/handle/11362/2686/2/S2006536_es.pdf

Nascimento, P. y Moreira, T. A. (2013). Desafíos y oportunidades sociales en la valorización de la tierra en Brasil. Revista Bitácora Urbano Territorial de la Universidad Nacional de Colombia, 22(1), 75-88. Recuperado de https://revistas.unal.edu.co/index.php/bitacora/article/view/75-88/ pdf_470

Pinilla, J. F. (2003). Evolución del sistema urbanístico colombiano: reflexión pendiente desde el derecho. Recuperado de http://www.institutodeestudiosurbanos.info/dmdocuments/cendocieu/Especializacion_Mercados/Documentos_Cursos/Evolucion_Sistema_Urbanistico-Pinilla_Juan2003.PDF

Ramírez, E. (2013). El cálculo del efecto plusvalía y su relación como instrumento de gestión con las actividades económicas adscritas al régimen de usos del suelo en el desarrollo urbano de Bogotá D. C. - Colombia [tesis de maestría. Universidad Javeriana. Bogotá. Colombia]. Recuperado de https://repository.javeriana.edu.co/bitstream/handle/10554/14010/RamirezPardoEdwin2013.pdf;jsessionid=08469F05BD13FEBC8A8E1B6641B91B$8 \mathrm{~F}$ ? sequence $=1$

República de Colombia (1936). Congreso de Colombia. Acto Legislativo 1 de 1936. Recuperado de http://www.suin-juriscol.gov.co/viewDocument.asp?id=1824914

República de Colombia (1989). Congreso de Colombia. Ley 9 de 1989. Por la cual se dictan normas sobre planes de desarrollo municipal, compraventa y expropiación de bienes y se dictan otras disposiciones. Recuperado de https://www.alcaldiabogota.gov.co/sisjurMantenimiento/normas/ Norma1.jsp?i=1175

República de Colombia (1995). Corte Constitucional de Colombia, Sala Plena. Sentencia C-595. M. P. Carlos Gaviria Díaz. Recuperado de http://www.corteconstitucional.gov.co/relatoria/1995/C-595-95.htm

República de Colombia (1997). Congreso de Colombia. Ley 388 de 1997. Ley de Ordenamiento Territorial. Recuperado de http://www.secretariasenado.gov.co/senado/basedoc/ley_0388_1997.html

República de Colombia (1998). Corte Constitucional de Colombia, Sala Plena. Sentencia C-495. M. P. Antonio Barrera Carbonell. Recuperado de http://www.corteconstitucional.gov.co/relatoria/1998/C-495-98.htm 
República de Colombia (2000). Congreso de Colombia. Ley 600 de 2000. Por la cual se establece el trámite de los procesos de responsabilidad fiscal de competencia de las contralorías.

República de Colombia (2005a). Tribunal Administrativo de Cundinamarca, Sección Primera, Subsección A. AP-2004-02536. M. P. Susana Buitrago Valencia. Recuperado de https://www.ramajudicial.gov.co/-/tribunal-administrativo-de-cundinamarca-seccion-primera-subseccio-64

República de Colombia (2005b). Consejo de Estado, Sala de lo Contencioso Administrativo, Sección Tercera. Sentencia 25000-23-25-000-200301499-01(AP). M. P. Germán Rodríguez Villamizar.

República de Colombia (2007). Corte Constitucional de Colombia, Sala Plena. Sentencia C-517. M. P. Rodrigo Escobar Gil. Recuperado de http://www.corteconstitucional.gov.co/relatoria/2007/c-517-07.htm

República de Colombia (2009). Consejo de Estado, Sala de lo Contencioso Administrativo, Sección Tercera. Sentencia 07001-23-31-000-199700705-01 (15662). M. P. Myriam Guerrero de Escobar. Recuperado de http:// www.consejodeestado.gov.co/documentos/boletines/PDF/07001-23-31-0001997-00705-01(15662).pdf

República de Colombia (2010). Consejo de Estado, Sala de lo Contencioso Administrativo, Sección Primera. Sentencia 25000-23-27-000-200501178-01(AP). M. P. Marco Antonio Velilla Moreno.

República de Colombia (2014). Corte Constitucional de Colombia, Sala Plena. Sentencia C-035. M. P. Luis Ernesto Vargas Silva. Recuperado de http://www.corteconstitucional.gov.co/relatoria/2014/C-035-14.htm

República de Colombia (2016a). Constitución Política de Colombia. Bogotá: Legis.

República de Colombia (2016b). Consejo de Estado, Sala de lo Contencioso Administrativo, Sección Cuarta. Sentencia 25000-23-37-000-201400444-01(22611). M. P. Martha Teresa Briceño de Valencia. Recuperado de https://consejo-estado.vlex.com.co/vid/656501777

República de Colombia (2016c). Consejo de Estado, Sala de lo Contencioso Administrativo, Sección Cuarta. Sentencia 25000-23-27-000-201100123-01(19658). M. P. Hugo Fernando Bastidas Barcenas. Recuperado de https://consejo-estado.vlex.com.co/vid/653842041

República de Colombia (2016d). Consejo de Estado, Sala de lo Contencioso Administrativo, Sección Cuarta. 25000-23-27-000-2012-0057401(21149). M. P. Martha Teresa Briceño de Valencia. Recuperado de https:// consejo-estado.vlex.com.co/vid/637665017 
República de Colombia (2017a). Consejo de Estado, Sala de lo Contencioso Administrativo, Sección Quinta. Sentencia 76001-23-33-000-201700031-02 (ACU). M. P. Carlos Enrique Moreno Rubio. Recuperado de https:// consejo-estado.vlex.com.co/vid/695441065

República de Colombia (2017b). Consejo de Estado, Sala de lo Contencioso Administrativo, Sección Tercera, Subsección C. Sentencia 8800123-31-000-2010-00026-02(AP). M. P. Jaime Enrique Rodríguez Navas.

República Oriental del Uruguay (2008). Ley 18308 de 2008. El Senado y la Cámara de Representantes de la República Oriental del Uruguay, Asamblea General. Ordenamiento Territorial y Desarrollo Sostenible. Recuperado de https://www.ecolex.org/es/details/legislation/ley-no-18308-normas-sobre-ordenamiento-territorial-y-desarrollo-sostenible-lex-faoc080341/

Sandroni, P. (2012). Plusvalía urbana, fuente de financiamiento de infraestructura: la experiencia de Brasil y Colombia. Buenos Aires: Fodeco. Recuperado de http://www.camarco.org.ar/File/GetPublicFile?id=1067

Smolka, M. O. (2013). Implementación de la recuperación de plusvalías en América Latina: políticas e instrumentos para el desarrollo urbano. Recuperado de http://www.lincolninst.edu/publications/policy-focus-reports/implementacion-la-recuperacion-plusvalias-en-america-latina/ node/103 